\title{
Progress on research on rodents and rodent-borne zoonoses in South-east Asia
}

\author{
Kim Blasdell ${ }^{\mathrm{A}}$, Frédéric Bordes ${ }^{\mathrm{B}}$, Kittipong Chaisiri ${ }^{\mathrm{C}}$, Yannick Chaval ${ }^{\mathrm{D}}$, Julien Claude ${ }^{\mathrm{B}}$, \\ Jean-François Cosson ${ }^{\mathrm{D}}$, Alice Latinne ${ }^{\mathrm{B}, \mathrm{E}}$, Johan Michaux ${ }^{\mathrm{E}, \mathrm{F}}$, Serge Morand ${ }^{\mathrm{C}, \mathrm{F}, \mathrm{G}, \mathrm{H}}$, \\ Marie Pagès ${ }^{\mathrm{B}, \mathrm{D}}$ and Annelise $\operatorname{Tran}^{\mathrm{F}}$

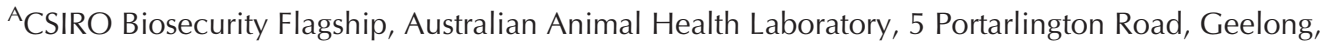 \\ Vic. 3220, Australia. \\ ${ }^{B}$ Institut des Sciences de l'Evolution, CNRS-IRD-UM2, Université de Montpellier 2, F-34093, Montpellier, France. \\ ${ }^{\mathrm{C}}$ Department of Helminthology, Faculty of Tropical Medicine, Mahidol University, Ratchathewi, Bangkok 10400, \\ Thailand. \\ DCentre de Biologie et de Gestion des Population, INRA, Campus International de Baillarguet, CS 30016, \\ 34988 Montferrier sur Lez, France. \\ E Department of Life Sciences-Conservation Genetics, University of Liège, Liège, 4000, Belgium. \\ ${ }^{\mathrm{F}}$ CIRAD, UR AGIRs, F-34398 Montpellier, France. \\ ${ }^{G}$ CNRS-CIRAD, Centre d'Infectiologie Christophe Mérieux du Laos, Vientiane, Laos. \\ ${ }^{\mathrm{H}}$ Corresponding author. Email serge.morand@univ-montp2.fr
}

\begin{abstract}
This review aims to synthesise knowledge regarding the taxonomy of South-east Asian murine rodents and the challenges associated with the identification of habitat preferences and associated rodent-borne diseases. Recent studies concerning the Rattini tribe have identified unclear species boundaries that would benefit from further investigation. The development of barcoding may allow more accurate identification of rodents, specifically for complex species. However, knowledge on the distribution and habitat specialisations of many common murine rodents is still scarce, particularly regarding the specific habitat preferences of most synanthropic rodent species (Rattus tanezumi or Rattus exulans). Several studies have analysed the prevalence of major rodent-borne diseases in South-east Asia and it appears that the greatest risk of rodent zoonoses are in the lowland rain-fed and irrigated landscapes, generally in and around rice fields.
\end{abstract}

Additional keywords: barcoding, habitat, phylogeny, Rattini, Rattus.

Received 19 August 2014, accepted 27 January 2015, published online 30 March 2015

\section{Introduction}

Rodents are recognised as hosts of at least 60 zoonotic diseases that represent a serious threat to human health (Meerburg et al. 2009). To better understand the potential epidemiology of an individual rodent-borne disease, first an accurate identification of the rodent host at the species level is required. For example, several studies have demonstrated that some rodent species considered as important reservoir hosts actually consist of several cryptic species (e.g. Rattus rattus species complex) or divergent mitochondrial (mt) DNA lineages (but see Robins et al. 2008; Lack et al. 2012), which may play different roles in the transmission of diseases. Once the rodent taxonomy has been defined, accurate identification of associated zoonotic pathogens and/or parasites is required, which requires the use of improved screening methods where possible (e.g. Ahmed et al. 2009; Al-Sabi and Kapel 2011). The risk to human health posed by major rodent-borne pathogens such as hantaviruses or Yersinia pestis (the agent of bubonic or pneumonic plague) illustrates the need to clearly identify rodent reservoirs and reservoir complexes (Haydon et al. 2002). Finally, information on the ecology, particularly in relation to habitat use, is also needed in order to identify high-risk environments and to better prevent and manage disease.

To understand disease ecology and parasite transmission, it must be considered that not all hosts are equally involved in parasite transmission, with some individuals or species being responsible for a disproportionate number of transmission events (Paull et al. 2012). Spatial factors are another source of heterogeneity, with some habitats or landscapes promoting either enhanced transmission or enhanced parasite and/or vector persistence (Ostfeld et al. 2005; Lambin et al. 2010).

This review aims to collate the current knowledge of Southeast Asian murine rodent taxonomy, diversity of associated pathogens and habitat preferences and relate this to the challenges encountered in obtaining these data. Many of the results presented here are the outcome of the recent CERoPath 
project (Community Ecology of Rodents and their Pathogens in a South-east Asian changing environment), which aimed at better understanding the relationships between rodent-borne diseases, rodents and their habitats using intensive field work, molecular screening and geospatial analyses (Pagès et al. 2010; Blasdell et al. 2011; Herbreteau et al. 2011; Dupuy et al. 2012; Bordes et al. 2013; Pumhom et al. 2014, 2015; Cosson et al. 2014; Jiyipong et al. 2015).

South-east Asia is a hot spot for both emerging infectious diseases (Coker et al. 2011) and threatened species (Sodhi et al. 2004; Wilcove et al. 2013), with the latter thought to be a significant contributing factor to the increase in outbreaks of infectious diseases (Morand et al. 2014). Asian rats are known to host numerous pathogens but are still difficult to identify to species level using morphological or karyotypic criteria (Badenhorst et al. 2009; Chaval et al. 2010). Moreover, reliable species identification is hampered by our imprecise knowledge of South-east Asian rat taxonomy, the lack of clear species limits within some genera (e.g. Rattus, Maxomys, Niviventer) and problematic access to reference specimens (Chaval et al. 2010; Pagès et al. 2010).

The habitat preferences of South-east Asian murine rodents are poorly known due primarily to a paucity of studies (Adler 1995; Adler et al. 1999; Aplin et al. 2003; Singleton et al. 2003; Wells et al. 2006, 2007). Moreover, most studies have assessed the potential impacts of rodents on agriculture or public health, and have focused primarily on peri-urban or agricultural areas (particularly rice paddy fields; Singleton 2003; Singleton et al. 2003, 2010; Brown et al. 2005; John 2014). Several studies focusing on conservation biology have investigated rodents in forested or limestone habitats (Wells et al. 2007; Rickart et al. 2011; Latinne et al. 2012, 2013a), but peridomestic species commonly found in households (e.g. Rattus exulans or $R$. tanezumi) have not been subject to extensive ecological investigation (Bordes et al. 2013) despite their invasive nature and likely high contact rates with humans (Kosoy et al. 2015).

In this review we first present recent results using molecular data to test the limits of the current taxonomy of the Rattini tribe. We aimed to establish where species boundaries are unclear and identify where further investigations are needed to provide a more rigorous systematic framework for epidemiological surveys. Second, we summarise recent findings on the habitat distribution and specialisation of the most common murine rodent species. Third, we present current knowledge on the association between rodents and the major rodent-borne diseases encountered in South-east Asia. We aimed specifically to identify synanthropic rodents and to establish their habitat specialisation, because these species are commonly hosts of significant rodent-borne diseases. Finally, we summarise recent analyses on rodent-borne diseases and the habitats that are more prone to hosting them (Herbreteau et al. 2012; Bordes et al. 2013; Chaisiri et al. 2015).

\section{Which reservoir rodents? Identifying rodent species, with a focus on the Rattini tribe}

South-east Asia is a hot spot of rodent diversification (Steppan et al. 2003; Robins et al. 2010; Fabre et al. 2013; Latinne et al. 2013b; Thomson et al. 2014). Within the Murinae, the Rattini tribe (Lecompte et al. 2008) encompasses 35 genera and 167 rat species (Musser and Carleton 2005). Nearly all representatives of this tribe inhabit South-east Asia, a major hot spot of biodiversity (Myers et al. 2000; Heaney 2011) under threat (Wilcove et al. 2013).

Asian rodents are difficult to discriminate morphologically at a specific level and the wide range of intraspecific morphological variation has resulted in a confused taxonomy with an overabundance of synonyms (e.g. 41 synonyms for $R$. norvegicus and 83 for $R$. rattus; Musser and Carleton 2005). Although in recent years molecular-based identification and species identification have been used to try to clarify the taxonomy (Robins et al. 2007; Galan et al. 2012), much still needs to be resolved.

Pagès et al. (2010) sequenced two mitochondrial and one nuclear gene from 122 rodent samples collected from Laos, Cambodia and Thailand to perform a phylogenetic analysis of the Rattini. Among other findings, that study showed that the Maxomys, Dacnomys (here Leopoldamys and Niviventer as sister taxa) and Rattus divisions (here Rattus, Bandicota and Berylmys) were sustained (Fig. 1). These results were congruent with the Murinae phylogeny obtained by Lecompte et al. (2008) and with the revised taxonomy of Rattini divisions proposed by Musser and Carleton (2005).

The phylogeny of Pagès et al. (2010) was further used to explore species boundaries using DNA sequence data themselves as the primary information source by applying the method of Pons et al. (2006), which detects the point of transition in the rate of lineage branching of a tree from interspecific long branches to intraspecific short burgeoning branching and identifies clusters of specimens corresponding to putative species. Twenty-four putative species were identified by Pagès et al. (2010). This estimated number of species is in agreement with the number of species described for this part of mainland South-east Asia (Thailand, Laos, Cambodia), with some exceptions (see Musser and Carleton 2005), in particular within the Berylmys and Rattus genera or Crunomys diversion. However, regardless of the method used, species delimitation depends on the evolutionary history of the species group and may fail due to incomplete lineage sorting, trans-species polymorphism, hybridisation and introgression (Leliaert et al. 2014).

Three putative species of Berylmys were identified in the sampling, whereas only two are mentioned in the literature within the geographic area surveyed (Berylmys bowersi and $B$. berdmorei). However, populations of $B$. bowersi in peninsular Thailand have previously been reported to be geographically isolated and to differ genetically from other populations (Francis 2008; Latinne et al. 2013a).

For the $R$. rattus species group, although five species have been described from this region (i.e. $R$. andamanensis, $R$. argentiventer, $R$. tanezumi, $R$. tiomanicus, and $R$. losea, which was not distinguished from $R$. sakeratensis in Pagès et al. 2010), the analysis corroborated the presence of an additional Rattus species (labelled 'R3' in Fig. 1). This putative species was identified previously as the diardii clade in the mitochondrial phylogeny of Robins et al. (2007) and, according to Aplin et al. (2011), could be a cryptic species. Pagès et al. (2013) used extensive sampling, morphological data and diverse genetic markers differing in rates of evolution and 


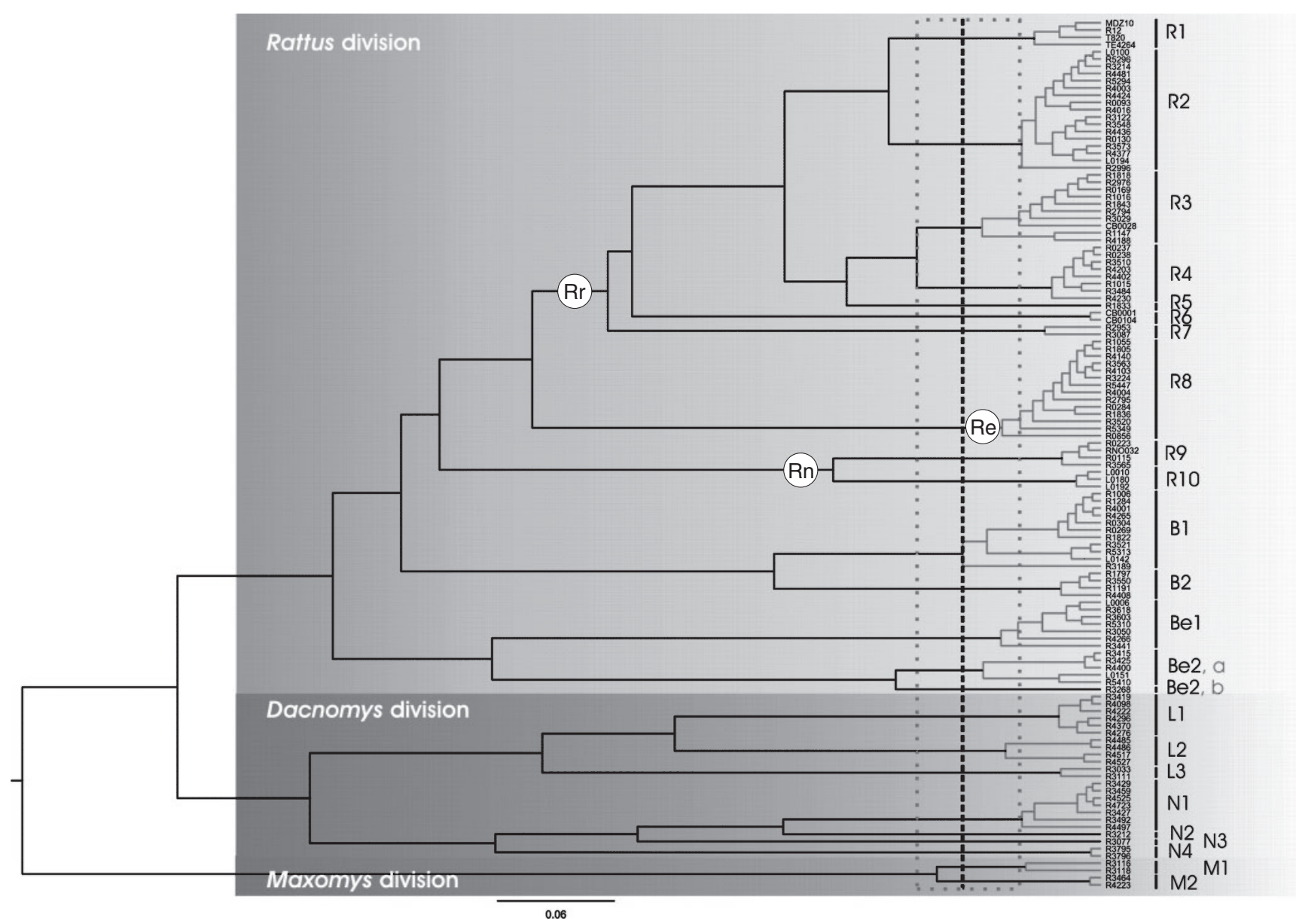

Fig. 1. Rattini ultrametric tree obtained with Multidivtime (freeware, available at http://statgen.ncsu.edu/thorne/multidivtime.html, accessed 10 March 2015) and clusters of specimens recognised as putative species by the method of Pons et al. (2006). Genetic clusters recognised as a putative species are highlighted and separated by longer black branches. The vertical bars group all sequences within each significant cluster, labelled R1 to M2 according to the genus to which they belong. Rr, Rattus rattus species group; Re, Rattus exulans species group; Rn, Rattus norvegicus species group. (R1, R. rattus; R2, Rattus tanezumi; R3, Rattus sp. (to be named); R4, Rattus sakeratensis; R5, Rattus tiomanicus; R6, Rattus argentiventer; R7, Rattus andamanensis; R8, R. exulans; R9, R. norvegicus; R10, Rattus nitidus; B1, Bandicota indica; B2, Bandicota savilei; Be1, Berylmys berdmorei; Be2a, Berylmys bowersi; Be2b, Berylmys sp.; L1, Leopoldamys edwardsi; L2, Leopoldamys neilli; L3, Leopoldamys sabanus; N1, Niviventer fulvescens; N2, Niviventer sp. 1; N3, Niviventer sp. 2; N4, Niviventer langbianis or Chiromyscus chiropus; M1, Maxomys sp.; M2, Maxomys surifer). Reproduced from Pagès et al. (2010).

parental inheritance (two mtDNA genes, one nuclear gene and eight microsatellite loci) to assess the reproductive isolation among $R$. tanezumi, $R$. sakeratensis and R3. Based on mtDNA data, three lineages were identified. Rattus tanezumi is phylogenetically isolated from the other two lineages, at a genetic distance of $5.72 \%$ from R3 and $6.84 \%$ from $R$. sakeratensis. In contrast, R3 and sakeratensis are closely related and separated by a shorter genetic distance $(3.80 \%)$. However, only two genetic entities were identified on the basis of nuclear data: $R$. sakeratensis and another entity comprising both R3 and $R$. tanezumi. Morphometric analyses based on external measurements (lengths of head+body, tail, hind foot, ear and head) were consistent with the nuclear genetic data, because these also did not separate the $R$. tanezumi and R3 mtDNA lineages in terms of either shape or size.

The occurrence of two highly divergent mtDNA lineages (i.e. R. tanezumi and R3) suggests that the Asian black rat has a complex evolutionary history (Aplin et al. 2011). The presence of highly divergent mtDNA lineages within a single large species may be the result of geographical structuring during Quaternary climatic oscillations, or introgression from a species yet to be identified, either of which could account for the incongruence between mtDNA and nuclear patterns in Asian black rats. Increasing the size of the sampling area would provide further insight into the evolutionary history underlying the great diversity of Asian black rats.

Based on phylogenetic, morphological and geographical evidence, Pagès et al. (2010) proposed to attribute names to the 24 species highlighted in their study. However, assigning the appropriate name to each species was a problematic task, particularly for the Rattini species, whose taxonomy is complicated by a large number of synonyms (see above). One taxonomic change that does seem well founded is the naming of the Rattus losea-like populations from the region comprising central and northern Thailand and the Vientiane plain of Laos. According to Aplin et al. (2011), these populations refer to Rattus 
sakeratensis, a group distinguished from true $R$. losea, restricted to Cambodia, Vietnam, China and Taiwan.

\section{Developing rodent barcoding}

Field identification poses difficulties for accurate species assignation in several genera of Rattini, as well as for the Mus species. Although modern morphometrics has proved to be more efficient (Chaval et al. 2010), it requires well-preserved skulls that are not always available, particularly as cleaning raw skulls is time consuming when applied to large surveys.

Because few taxonomists can morphologically identify species, it has been proposed that an international consortium be developed, the Barcoding of Life (BOL), which aims at promoting and developing molecular identification of living organisms. DNA barcoding systems use a short, standardised gene region to identify species (usually the mitochondrial cytochrome $c$ oxidase I (COI) gene) in association with morphological voucher specimens to validate the molecular identification (Hajibabaei et al. 2007).

Of the available DNA markers, a 648-bp region of the $C O I$ gene was chosen in agreement with the BOL (Pagès et al. 2013). For South-east Asian rodents, the COI gene was found to be highly relevant for species assignment because clear and robust species-specific clades were retrieved (with the notable exception of the Asian black rat complex; Pagès et al. 2013; and see above).

The barcoding technique has several advantages, including the requirement for small tissue pieces and the fact that it can be readily applied to museum samples. For example, Latinne et al. (2013a) investigated the diversity and endemism of Rattini in Thai limestone karsts and confirmed the existence of the species Niviventer hinpoon in several new localities using as reference a small DNA fragment obtained from the holotype. This work illustrates the huge opportunities ancient DNA analysis may offer to taxonomists (Willerslev and Cooper 2005; Rohland and Hofreiter 2007; for rodents, see Wyatt et al. 2008; Aplin et al. 2011).

Galan et al. (2012) have developed a time- and cost-effective method suitable for barcoding thousands of samples using the 454 GS FLX platform (Roche Diagnostics Corporation, Basel, Switzerland). The originality of this approach resides in the use of: (1) a high-level resolution mini-barcode of a 136-bp region of the cytochrome $b$ gene suitable for identification of individuals at the specific level from tissue samples and degraded DNA (non-invasive samples, including hairs and faeces, and museum specimens); (2) combined polymerase chain reaction (PCR)-tagged primers, which enable attribution of each read to a unique sample after 454 sequencing, which could contain a mixture of different species; and (3) software associated with the GenBank database for read analysis and species identification. The relevance of this innovative approach for rodent species barcoding was validated on a reference sample (Galan et al. 2012) comprising 265 rodent individuals corresponding to 103 species from Asia, Africa and Europe, whose species identification was clearly established beforehand using molecular and/or morphological characters. This method identified $100 \%$ of samples at the specific level for samples collected in geographic areas where the rodent fauna is well documented by molecular data in public databanks.
Molecular identification combined with high-throughput sequencing allows fast, accurate and inexpensive species identification. As an example, the reference database for the mini-barcode has been added to the online barcoding tool RodentSEA for rodent identification (http://www.ceropath.org, accessed 28 February 2015). However, a major caveat of the barcoding identification method, when based on a single gene, is that it will fail to detect introgression (Pagès et al. 2013), which needs a combination of methods for accurate species determination (e.g. mtDNA, nuclear marker and/or morphology).

\section{Identifying rodent habitat preferences}

Environmental change, including habitat disturbance, urbanisation and biodiversity loss, affect the location and densities of parasites, hosts and vectors (Ostfeld et al. 2005; Gillespie and Chapman 2008; Ostfeld 2009). Because particular hosts and environments may contribute disproportionately to parasite transmission, the challenge is to identify their relative importance in order to predict disease persistence or emergence (Paull et al. 2012).

Recently, two concepts have emerged: (1) 'synanthropic species', namely species ecologically associated with humans; and (2) 'generalist' species, which are species living in peridomestic habitats or those that often invade disturbed habitats (McFarlane et al. 2012). In a comparative study performed in the Asian-Australian region, McFarlane et al. (2012) found that wild mammal hosts (primarily rodents and bats) of zoonotic emerging infectious diseases are 15-fold more likely to inhabit human-modified environments. That is, human-induced disturbances often increase the distribution and abundance of generalist rodent species, which are frequently important reservoirs of human pathogens.

Synanthropic rodent species with a preference for settlements and agricultural environments should be targeted for pest control, because it is these species and the diseases they carry that humans will be most commonly exposed to. Moreover, these species most likely benefit from the ongoing human modification of habitats, which led Singleton et al. (2010) to emphasise: 'rodent damage to agricultural production is a landscape problem that can be managed only by a widespread landscape approach'. These observations may apply worldwide because similar findings have been made in Brazil (Püttker et al. 2008) and eastern Africa (Makundi and Massawe 2011).

Palmeirim et al. (2014) evaluated the patterns of spatial distribution and specialisation of common murine rodents inhabiting South-east Asian landscapes. For this, they used the extensive geo-referenced rodent trapping database collected from Thailand, Cambodia and Laos. To illustrate the distribution of rodent species across habitat types, multivariate analysis was performed on the number of rodent individuals trapped in each of four main types of habitat: forest, agriculture on dry lands, agriculture on rain-fed or irrigated lands (i.e. paddy fields) and human settlements (isolated houses and villages). The principal component analysis (PCA) plot obtained in that analysis (Fig. 2a) showed the associations between the rodent species and habitat types. Several rodent species exhibited specialised habitat preferences: $R$. norvegicus and $R$. exulans in human settlements; Rattus argentiventer, $R$. sakeratensis, 
(a)

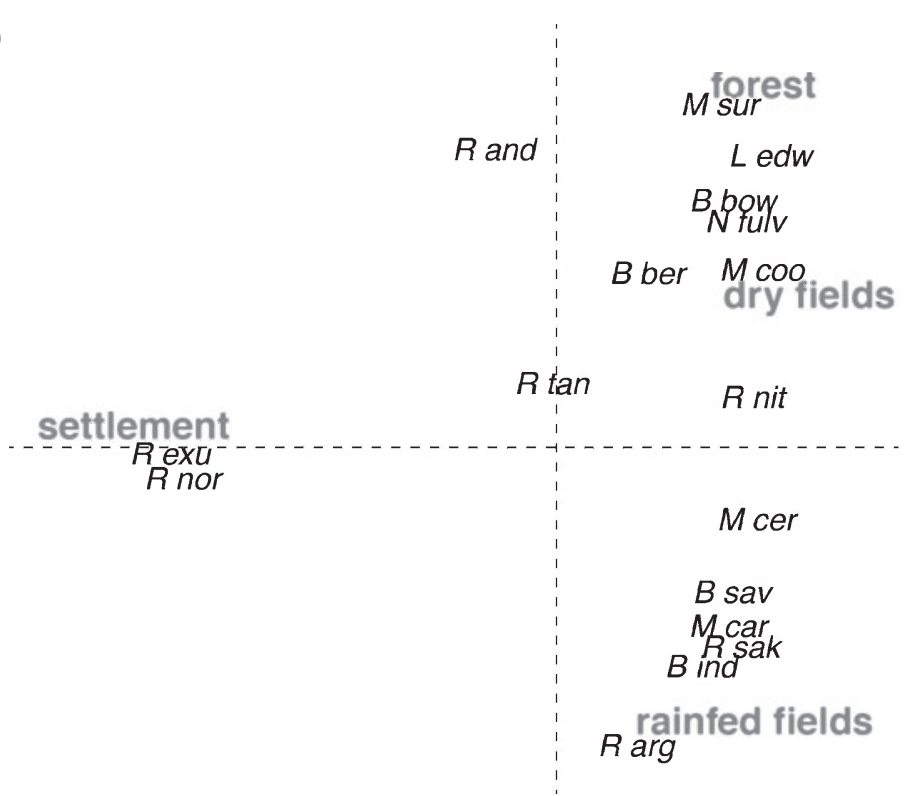

(b)

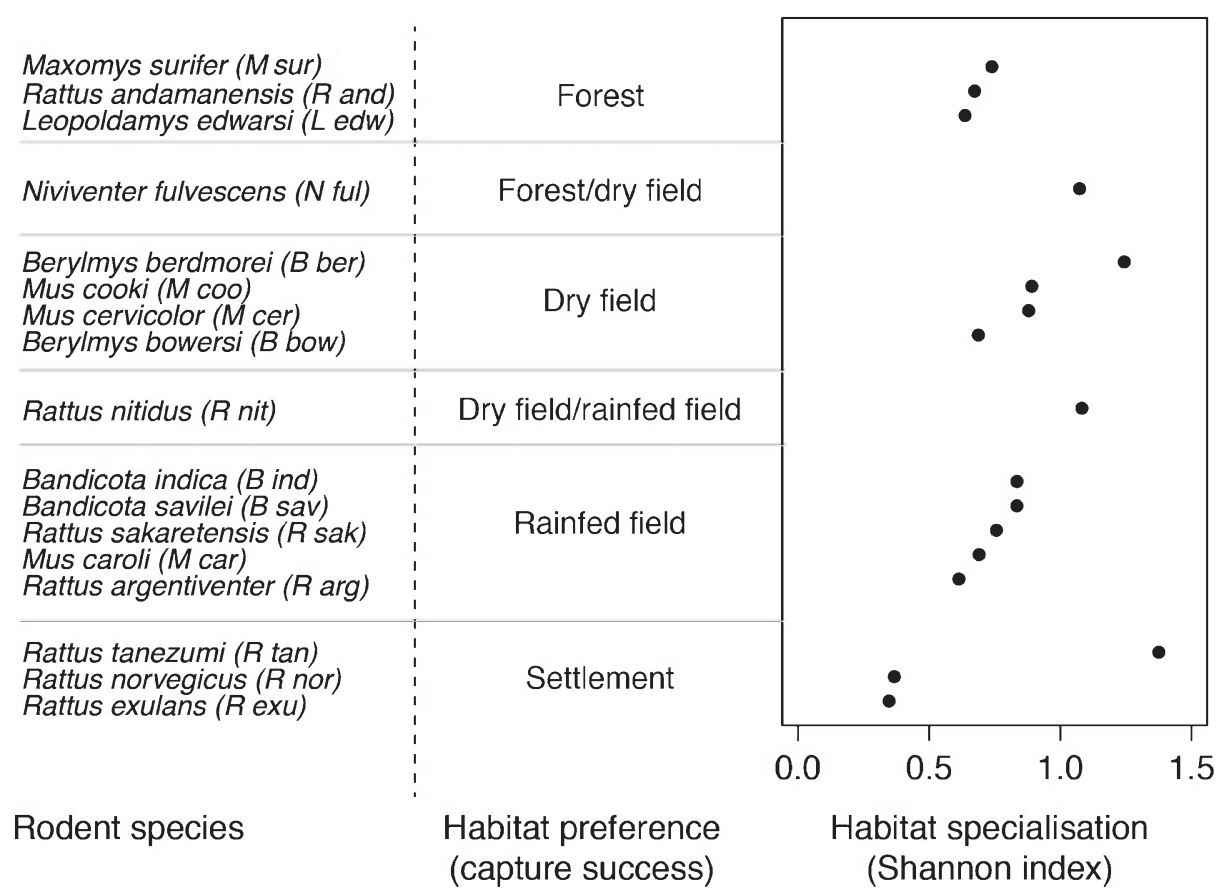

Fig. 2. (a) Distribution of rodent species according to habitat types: lowland rain-fed (paddy fields), nonflooded land (dry lands), forest and settlement (houses) on the two first axes of a principal component analysis (PCA). Dimensions 1 and 2 accounted for $80 \%$ of the variance. B ind, Bandicota indica; B sav, Bandicota savilei; Be ber, Berylmys berdmorei; Be bow, Berylmys bowersi; M sur, Maxomys surifer; M car, Mus caroli; $\mathrm{M}$ cer, Mus cervicolor; $\mathrm{M}$ coo, Mus cookii; $\mathrm{M}$ ful, Niviventer fulvescens; $\mathrm{R}$ arg, Rattus argentiventer; $\mathrm{R}$ exu, Rattus exulans; R nit, Rattus nitidus; R sak, Rattus sakeratensis; $\mathrm{R}$ nor, Rattus norvegicus; $\mathrm{R}$ tan, Rattus tanezumi. Redrawn after Palmeirim et al. (2014). (b) Ranking of rodent species according to their habitat specialisation (Shannon index) with main habitat preference (based on capture success) corresponding to the habitat (or two habitats) in which a higher number of captures have been obtained (calculated using the data from Palmeirim et al. 2014). 
Bandicota indica and Mus caroli in rain-fed fields; Mus cookii and Berylmys berdmorei in non-flooded lands; and Maxomys surifer and Leopoldamys edwardsi in forests. Some other species exhibited more generalist tendencies, including Niviventer fulvescens, which was found in forests or non-flooded lands, and Rattus nitidus found in rain-fed fields or non-flooded lands. Finally, $R$. tanezumi showed low habitat preference and was found in many habitat types, including households.

The specialisation of rodent species to the four types of habitat can be assessed using the Shannon index (Morand et al. 2015). Rodent species were ranked according to the value of the Shannon index and this was then compared with the value of their habitat type preference (i.e. for which the highest number of individual rodents of each species were trapped). The ranking of rodent species according to their habitat specialisation (using Shannon index based on data presented in Palmeirim et al. 2014) illustrated the PCA results (Fig. 2b). The level of habitat specialisation appeared to be independent of habitat preference (i.e. the habitat with the highest capture success). Whereas the synanthropic species $R$. exulans and $R$. norvegicus showed high specialisation to settlement habitat, the other synanthropic species $R$. tanezumi showed the lowest specialisation of all rodent species.

The results also provided new insights into the importance of the landscape structure on the probability of rodent presence in several habitat types in South-east Asia. The status of specialist species and/or synanthropic species for several rodent species was confirmed, although the majority of rodent species exhibited some degree of habitat specialisation. A few species showed clear preference for forested areas, such as L. edwardsi and M. surifer, at the quasi-exclusion of other habitats (i.e. agriculture lands). This pattern has been described previously for similar largebodied rodent species, including Leopoldamys sabanus, Maxomys rajah and Maxomys whiteheadi by Charles and Ang (2010) in Brunei. However, most species exhibited lower habitat specificity and were found either in forested areas and dry-lands (B. bowersi, N. fulvescens) or in rain-fed fields and dry-lands (M. cervicolor, B. savilei).

\section{Identifying rodent-borne diseases in rodents}

Rodents are reservoirs and hosts of many viruses, bacteria and protists of public health concern (Meerburg et al. 2009). In Southeast Asia, most studies have focused on mainland countries (and principally Thailand; Herbreteau et al. 2012; Bordes et al. 2013), establishing the presence of several important zoonoses in the region. Viruses investigated have included hantaviruses (the agents of haemorrhagic fever with renal syndrome (HFRS); Blasdell et al. 2011), lymphocytic choriomeningitis virus (LCMV; Nitatpattana et al. 2000) and rabies virus (Brown et al. 1979). All these viruses can be transmitted directly between rodent hosts, although transmission of hantaviruses and LCMV likely also occurs through exposure to aerosolised infectious excretions (Monath 1975; Armstrong et al. 1995). Among the bacteria, three genera in particular have been a major focus: Leptospira spp., agents of leptospirosis (Thaipadungpanit et al. 2007; Ivanova et al. 2012; Cosson et al. 2014); Bartonella spp., agents of bartonellosis (Castle et al. 2004; Saisongkorh et al. 2009; Jiyipong et al. 2012,
2015); and Orientia tsutsugamushi (Coleman et al. 2003), the agent of scrub typhus. Bartonella spp. and O. tsutsugamushi are arthropod-borne agents, whereas Leptospira spp. are transmitted indirectly via contact with water or soils contaminated by the urine of infected rodents. Recently, Bordetella hinzii was also identified in rodents (Jiyipong et al. 2013). This species causes respiratory disease in poultry and has occasionally been described in humans (Gadea et al. 2000). From the three predominantly investigated protists, Toxoplasma gondii (Jittapalapong et al. 2011) is a significant human pathogen, whereas Trypanosoma spp. (Jittapalapong et al. 2008; Milocco et al. 2013; Pumhom et al. 2014) and Babesia spp. (Dantrakool et al. 2004) primarily infect livestock and more rarely humans.

Herbreteau et al. (2012) targeted rodent reservoirs in Thailand using published studies that screened for microparasites (viruses, bacteria and protists; Fig. 3). They proposed a simple method for prioritising and/or targeting rodents that are the dominant carriers of rodent-borne diseases by assuming that they harbour more pathogen species than expected on the basis of the relationship between pathogen richness and sampling effort. They found that microparasite richness was correlated with both rodent sample size and pathogen screening effort, and suggested that the residual variation of this correlation could help identify major rodent reservoirs and potential risky habitats. Using the residual variations of microparasite richness among rodent hosts, Herbreteau et al. (2012) showed that several rodent species harboured more pathogens than expected by the regression model (i.e. positive residual values), particularly Rattus adamanensis, Bandicota savilei, $R$. argentiventer and $R$. norvegicus. Two species appeared to harbour fewer pathogen species than expected by the regression model (i.e.

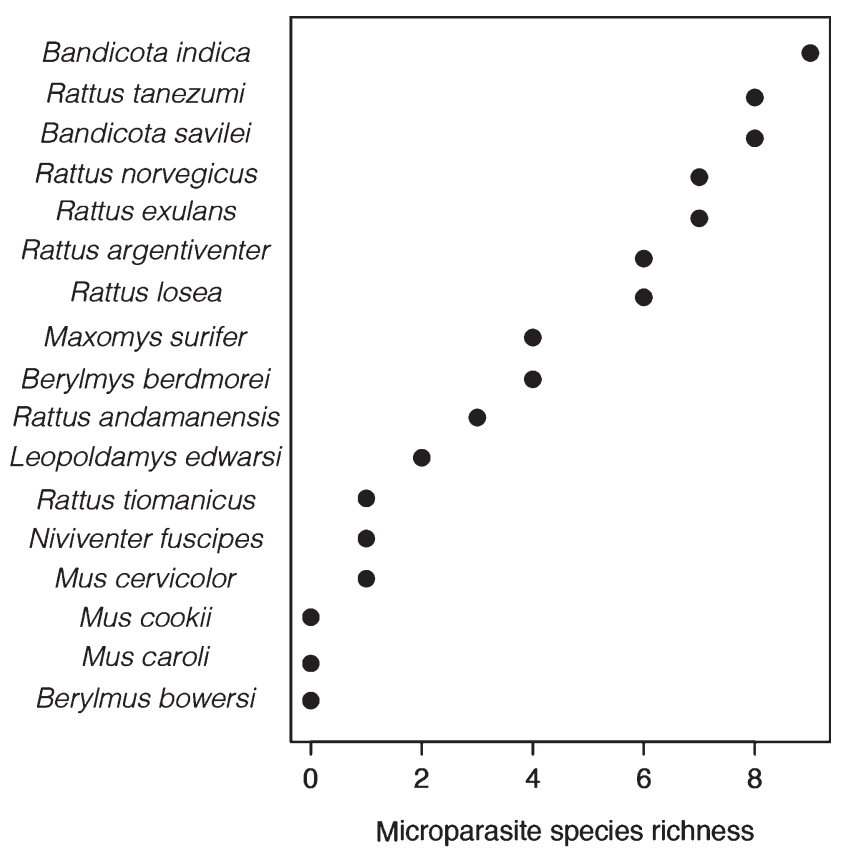

Fig. 3. Total number of known viruses, bacteria and protists causing major rodent-borne diseases in rodents from Thailand (data from Herbreteau et al. 2012). 
have high negative residuals values): Mus cervicolor and M. caroli.

Zoonotic helminths have also been extensively investigated in Asian rodents (for a review, see Chaisiri et al. 2015). A recent and intensive survey concerned 2478 rodent individuals trapped, with $735(29.7 \%)$ found to be infected by the following zoonotic helminth species: Echinostoma malayanum, Echinostoma ilocanum, Plagiorchis muris, Raillietina sp., Hymenolepis diminuta, Hymenolepis nana, Cyclodontostomum purivisi and Moniliformis moniliformis (Chaisiri et al. 2015; Palmeirim et al. 2014). Infections with most of these zoonotic helminths are usually asymptomatic in humans (Hong et al. 1996; Chero et al. 2007). The three synanthropic rodents $R$. tanezumi, $R$. exulans and $R$. norvegicus were identified as reservoirs for all these pathogens. Among these rodent species, $R$. tanezumi appeared to play a major role as a reservoir host, with individuals found positive for seven of these zoonotic helminth species (Chaisiri et al. 2015).

\section{Associating rodent-borne diseases with rodent habitats}

Herbreteau et al. (2012) found that higher pathogen richness than expected from correlation with sampling effort (i.e. positive residual values) was found in non-flooded lands, forests and paddy fields. Because of the limited number of surveys that included non-flooded lands and forests, the results from these habitats should be considered with caution. However, because numerous surveys have focused on paddy rice fields and households, the findings for these habitats should be relatively robust.

Bordes et al. (2013) took a different approach, using information from a field spatial study that investigated the distribution of murid rodents in various habitats in three countries in South-east Asia (Dupuy et al. 2012) and compared this with their infection status by 10 taxa of microparasites, based on data acquired from the published literature. Microparasite species richness was calculated by rodent species on 20272 rodents belonging to 13 species (according to the identification provided by the published studies). Statistical analyses were performed to identify how microparasite diversity differs as the average distance between the trapping site of individual rodents and five categories of land cover (forest, steep agriculture land, flat agriculture land, water and built-up surfaces) varied. The analyses of Bordes et al. (2013) found that microparasite diversity was positively associated with flat agricultural land, meaning rice fields, the main agricultural landscape in South-east Asia (Xiao et al. 2006). This result suggests that rice fields may favour microparasite transmission and should be targeted for rodent-borne disease surveillance and rodent control. This is because even if only a small percentage of smallholder farmers are debilitated by rodent-borne diseases, this will impact not only on public health, but also on regional food security (Meerburg et al. 2009; Singleton et al. 2010; John 2014).

\section{Conclusion}

Thanks to the increasing application of molecular systematics, recent studies have succeeded in refining the taxonomy of one of the most difficult groups of mammals (Aplin et al. 2011;
Galan et al. 2012). Most of the species expected in the region of South-east Asia studied were confirmed using this method, but new putative species limits were also indicated, in particular within the Berylmys, Maxomys and Rattus genera, where future taxonomic studies should be directed. The studies presented in this review have laid the foundations to better investigate rodentborne diseases in South-east Asia and illustrate the relevance of evolutionary studies to public health. However, to truly assess the risk to human health in the region, accurate identifications of pathogens and parasites hosted by these rodents are also needed. To enable this, the development of barcoding techniques (including the sharing of protocols and concepts), biobanking (in particular for parasites and/or pathogens hosted by rodents) and ebanking (including the accessibility and sharing of georeferenced data, collections and tissues) is required (Morand and Clairon 2014).

Another challenge is to identify specific environmental determinants that explain higher rodent parasite burdens in human-dominated areas. Although certain associations exist between a particular disease in humans and the presence of a given host reservoir species, infection in humans is not always congruent with distribution of that host, suggesting that other factors are at work. Moreover, identifying a reservoir for a single parasite may be rather restrictive due to the circulation of multiple pathogens in natural systems. Multiple infection is the rule, but has only recently been considered as a key factor in wild ecosystems (Telfer et al. 2008; Bordes and Morand 2009).

A final challenge is related to the invasion or range expansion of rodents. The black rat ( $R$. rattus), Norwegian rat ( $R$. norvegicus), Asian house rat ( $R$. tanezumi) and Pacific rat ( $R$. exulans), like the house mouse (Mus musculus domesticus), have radically and explosively expanded their geographic range as a consequence of human activities. All these Rattus species originated in Asia, and can be found in sympatry in South-east Asia due to their synanthropic behaviour. These rodents have been implicated (Kuo et al. 2011), and still are implicated (Kosoy et al. 2015), in the emergence and spread of infectious diseases of public health importance, such as plague, murine typhus, scrub typhus, leptospirosis, hantavirus and haemorrhagic fever, among others. A better understanding of the range extension mechanisms and consequences would require specific investigation of the genetics (phylogeography, population genetics) and immunology (immunogenetics) of these rodent species.

Parasitic risk is global, with many parasite species harbouring zoonotic tendencies. This review demonstrates that comparative analyses can help identify rodent reservoirs and environments that present a high risk of multiple rodent-borne diseases. Because pathogen richness varies between both rodent species and habitats, the results from the studies presented herein demonstrate the need for future studies in Asian ecosystems. Such studies would greatly improve our understanding of the processes involved in the transmission ecology of rodent-borne diseases in the region.

\section{Acknowledgements}

The authors' work reported herein was funded by the French ANR Biodiversity (grant no. ANR 07 BDIV 012 CERoPath project ('Community Ecology of Rodents and their Pathogens in a changing 
environment'); http://www.ceropath.org, accessed 28 February 2015) and by the French ANR CP\&ES (grant no. ANR 11 CPEL 002 BiodivHealthSEA project ('Local impacts and perceptions of global changes: biodiversity, health and zoonoses in South-east Asia'); http://www.biodivhealthsea.org, accessed 28 February 2015). The authors thank the CERoPath team, with special thanks to the drivers, for help during fieldwork.

\section{References}

Adler, G. H. (1995). Habitat relations within lowland grassland rodent communities in Taiwan. Journal of Zoology 237, 563-576. doi:10.1111/j.1469-7998.1995.tb05015.x

Adler, G. H., Mangan, S. A., and Suntsov, V. (1999). Richness, abundance, and habitat relations of rodents in the Lang Bian mountains of southern Viet Nam. Journal of Mammalogy 80, 891-898. doi:10.2307/1383257

Ahmed, A., Engelberts, M. F. M., Boer, K. R., Ahmed, N., and Hartskeerl, R. A. (2009). Development and validation of a real-time PCR for detection of pathogenic leptospira species in clinical materials. PLOS ONE 4, e7093. doi:10.1371/journal.pone.0007093

Al-Sabi, M. N. S., and Kapel, C. M. O. (2011). Multiplex PCR identification of Taenia spp. in rodents and carnivores. Parasitology Research 109, 1293-1298. doi:10.1007/s00436-011-2373-9

Aplin, K. P., Brown, P. R., Jacob, J., Krebs, C., and Singleton, G. R. (2003). 'Field methods for rodent Studies in Asia and the Indo-Pacific.' Australian Centre for International Agricultural Research Monograph No. 100 (Australian Centre for International Agricultural Research: Canberra.)

Aplin, K., Suzuki, H., Chinen, A. A., Chesser, R. T., Ten Have, J., Donnellan, S. C., Austin, J., Frost, A., Gonzalez, J.-P., Herbreteau, V., Catzeflis, F., Soubrier, J., Fang, Y.-P., Robins, J., Matisoo-Smith, E., Bastos, A. D. S., Maryanto, I., Sinaga, M. H., Denys, C., Van Den Bussche, R. A., Conroy, C., Rowe, K., and Cooper, A. (2011). Multiple geographic origins of commensalism and complex dispersal history of Black Rats. PLoS ONE 6, e26357. doi:10.1371/journal.pone.0026357

Armstrong, L. R., Zaki, S. R., Goldoft, M. J., Todd, R. L., Khan, A. S., Khabbaz, R. F., Ksiazek, T. G., and Peters, C. J. (1995). Hantavirus pulmonary syndrome associated with entering or cleaning rarely used, rodent-infested structures. The Journal of Infectious Diseases 172, 1166. doi:10.1093/infdis/172.4.1166

Badenhorst, D., Herbreteau, V., Chaval, Y., Page, M., Robinson, T. J., Rerkamnuaychoke, W., Morand, S., Hugot, J.-P., and Dobigny, G. (2009). New karyotypic data for Asian rodents (Rodentia, Muridae) with the first report of B-chromosomes in the genus Mus. Journal of Zoology 279, 44-56. doi:10.1111/j.1469-7998.2009.00588.x

Blasdell, K., Cosson, J.-F., Chaval, Y., Herbreteau, V., Douangboupha, B., Jittapalapong, S., Lundqvist, A., Hugot, J.-P., Morand, S., and Buchy, P. (2011). Rodent-borne hantaviruses in Cambodia, Laos PDR and Thailand. EcoHealth 8, 432-443. doi:10.1007/s10393-011-0725-7

Bordes, F., and Morand, S. (2009). Parasite diversity: an overlooked metric of parasite pressures? Oikos 118, 801-806. doi:10.1111/j.1600-0706. 2008.17169.x

Bordes, F., Herbreteau, V., Dupuy, S., Chaval, Y., Tran, A., and Morand, S. (2013). The diversity of microparasites of rodents: a comparative analysis that helps in identifying rodent-borne rich habitats in Southeast Asia. Infection Ecology and Epidemiology 3, 20178. doi:10.3402/iee.v3i0. 20178

Brown, J. L., Tingpalapong, M., and Andrews, W. K. (1979). Serological survey of feral rodents in Thailand for evidence of rabies virus infection. Journal of Wildlife Diseases 15, 601-606. doi:10.7589/0090-355815.4.601

Brown, P. B., Phu Tuan, N., Singleton, G. R., Thi Hue, D., Thi Hoa, P., Thi Thu Ha, P., Quang Tan, T., and Van Tuat, N. (2005). Population dynamics of Rattus argentiventer, Rattus losea, and Rattus rattus inhabiting a mixed-farming system in the red river delta, Vietnam. Population Ecology 47, 247-256. doi:10.1007/s10144-005-0228-x
Castle, K. T., Kosoy, M., Lerdthusnee, K., Phelan, L., Bai, Y., Gage, K. L., Leepitakrat, W., Monkanna, T., Khlaimanee, N., Chandranoi, K., Jones, J. W., and Coleman, R. E. (2004). Prevalence and diversity of Bartonella in rodents of northern Thailand: a comparison with Bartonella in rodents from southern China. The American Journal of Tropical Medicine and Hygiene 70, 429-433.

Chaisiri, K., Siribat, P., Ribas, A., and Morand, S. (2015). Potentially zoonotic helminthiases of murid rodents from the Indo-Chinese peninsula: impact of habitat and the risk of human infection. Vector-Borne and Zoonotic Diseases (Larchmont, N.Y.) 15, 73-85. doi:10.1089/vbz.2014. 1619

Charles, J. K., and Ang, B. B. (2010). Non-volant small mammal community responses to fragmentation of kerangas forests in Brunei Darussalam. Biodiversity and Conservation 19, 543-561. doi:10.1007/s10531-0099691-6

Chaval, Y., Dobigny, G., Michaux, J., Cosson, J. F., and Herbreteau, V. (2010). A multi-approach survey as the most reliable tool to accurately assess biodiversity: an example of Thai murine rodents. Kasetsart Journal of Natural Sciences 44, 590-603.

Chero, J. C., Saito, M., Bustos, J. A., Blanco, E. M., Gonzalvez, G., and Garcia, H. H. (2007). Hymenolepis nana infection: symptoms and response to nitazoxanide in field conditions. Transactions of the Royal Society of Tropical Medicine and Hygiene 101, 203-205. doi:10.1016/ j.trstmh.2006.04.004

Coker, R. J., Hunter, B. M., Rudge, J. W., Liverani, M., and Hanvoravongchai, P. (2011). Emerging infectious diseases in Southeast Asia: regional challenges to control. Lancet 377, 599-609. doi:10.1016/S0140-6736 (10)62004-1

Coleman, R. E., Taweesak, M., Linthicum, K. T., Monkanna, T., Linthicum, K. J., Strickman, D. A., Frances, S. P., Tanskul, P., Kollars, T. M. Jr, Inlao, I., Watcharapichat, P., Khlaimanee, N., Phulsuksombati, D., Sangjun, N., and Lerdthusnee, K. (2003). Occurrence of Orientia tsutsugamushi in small mammals from Thailand. The American Journal of Tropical Medicine and Hygiene 69, 519-524.

Cosson, J.-F., Picardeau, M., Mielcarek, M., Tatard, C., Chaval, Y., Suputtamongkol, Y., Buchy, P., Jittapalapong, S., Herbreteau, V., and Morand, S. (2014). Epidemiology of Leptospira transmitted by rodents in Southeast Asia. PLoS Neglected Tropical Diseases 8, e2902. doi:10.1371/journal.pntd.0002902

Dantrakool, A., Somboon, P., Hashimoto, T., and Saito-Ito, A. (2004). Identification of a new type of Babesia species in wild rats (Bandicota indica) in Chiang Mai province, Thailand. Journal of Clinical Microbiology 42, 850-854. doi:10.1128/JCM.42.2.850-854.2004

Dupuy, S., Herbreteau, V., Feyfant, T., Morand, S., and Tran, A. (2012). Landcover dynamics in southeast Asia: contribution of object-oriented techniques for change detection. In: 'Proceedings of the 4th International Conference on GEographic Object-Based Image Analysis (GEOBIA)'. (Ed. R. Queiroz Feitosa) pp. 217-222. (Pontifícia Universidade Católica do Rio de Janeiro: Rio de Janeiro.)

Fabre, P.-H., Pagès, M., Musser, G. G., Fitriana, Y. S., Fjeldså, J., Jennings, A., Jønsson, K. A., Kennedy, J., Michaux, J., Semiadi, G., Supriatna, N., and Helgen, K. M. (2013). A new genus of rodent from Wallacea (Rodentia: Muridae: Murinae: Rattini), and its implication for biogeography and Indo-Pacific Rattini systematics. Zoological Journal of the Linnean Society 169, 408-447. doi:10.1111/zoj.12061

Francis, C. M. (2008). 'A Field Guide to the Mammals of South-East Asia.' (New Holland: London.)

Gadea, I., Cuenca-Estrella, M., Benito, N., Blanco, A., Fernández-Guerrero, M. L., Valero-Guillén, P. L., and Soriano, F. (2000). Bordetella hinzii, a 'new' opportunistic pathogen to think about. The Journal of Infection 40, 298-299. doi:10.1053/jinf.2000.0646

Galan, M., Pagès, M., and Cosson, J.-F. (2012). Next-generation sequencing for rodent barcoding: species identification from fresh, degraded and environmental samples. PLOS ONE 7, e48374. doi:10.1371/journal. pone. 0048374 
Gillespie, T. R., and Chapman, C. (2008). Forest fragmentation, the decline of an endangered primate, and changes in host-parasite interactions relative to an unfragmented forest. American Journal of Primatology 70, 222-230. doi:10.1002/ajp.20475

Hajibabaei, M., Singer, G. A., Hebert, P. D. N., and Hickey, D. A. (2007). DNA barcoding: how it complements taxonomy, molecular phylogenetics and population genetics. Trends in Genetics 23, 167-172. doi:10.1016/j.tig.2007.02.001

Haydon, D. T., Cleaveland, S., Taylor, L. H., and Laurenson, M. K. (2002). Identifying reservoirs of infection: a conceptual and practical challenge. Emerging Infectious Diseases 8, 1468-1473. doi:10.3201/eid0812. 010317

Heaney, L. R. (2011). Discovering diversity: studies of the mammals of Luzon island, Philippines. Fieldiana Life and Earth Sciences 2, 88-95. doi:10.3201/eid0812.010317

Herbreteau, V., Jittapalapong, S., Rerkamnuaychoke, W., Chaval, Y., Cosson, J.-F., and Morand, S. (Eds). (2011). 'Protocols for field and laboratory rodent studies.' (Kasetsart University Press: Bangkok.)

Herbreteau, V., Bordes, F., Jittapalapong, S., Supputamongkol, Y., and Morand, S. (2012). Rodent-borne diseases in Thailand: targeting rodent carriers and risky habitats. Infection Ecology \& Epidemiology 2, 2-6. doi:10.3402/iee.v2i0.18637

Hong, S. J., Woo, H. C., and Chai, J. Y. (1996). A human case of Plagiorchis muris (Tanabe, 1922: Digenea) infection in the Republic of Korea: freshwater fish as a possible source of infection. The Journal of Parasitology 82, 647-649. doi:10.2307/3283795

Ivanova, S., Herbreteau, V., Blasdell, K., Chaval, Y., Buchy, P., Guillard, B., and Morand, S. (2012). Leptospira and rodents in Cambodia: environmental determinants of infection. The American Journal of Tropical Medicine and Hygiene 86, 1032-1038. doi:10.4269/ajtmh. 2012.11-0349

Jittapalapong, S., Inpankaew, T., Sarataphan, N., Herbreteau, V., Hugot, J.-P., Morand, S., and Stich, R. W. (2008). Molecular detection of divergent trypanosomes among rodents of Thailand. Infection, Genetics and Evolution 8, 445-449. doi:10.1016/j.meegid.2007.08.002

Jittapalapong, S., Sarataphan, N., Maruyama, S., Hugot, J.-P., Morand, S., and Herbreteau, V. (2011). Seroprevalence of Toxoplasma gondii infections of rodents in Thailand. Vector Borne and Zoonotic Diseases (Larchmont, N.Y.) 11, 231-237. doi: $10.1089 / \mathrm{vbz} .2009 .0238$

Jiyipong, T., Jittapalapong, S., Morand, S., Raoult, D., and Rolain, J.-M. (2012). Prevalence and genetic diversity of Bartonella spp. in small mammals from southeastern Asia. Applied and Environmental Microbiology 78, 8463-8466. doi:10.1128/AEM.02008-12

Jiyipong, T., Morand, S., Jittapalapong, S., Raoult, D., and Rolain, J.-M. (2013). Bordetella hinzii in rodent, Southeast Asia. Emerging Infectious Diseases 19, 502-503. doi:10.3201/eid1903.120987

Jiyipong, T., Jittapalapong, S., Morand, S., and Rolain, J.-M. (2014). Bartonella species in small mammals and their potential vectors in Asia. Asian Pacific Journal of Tropical Biomedicine 4, 757-767.

Jiyipong, T., Morand, S., Jittapalapong, S., Raoult, D., and Rolain, J.-M. (2015). Bartonella spp. infections in rodents of Cambodia, Lao PDR and Thailand: identifying risky habitats. Vector-Borne and Zoonotic Diseases (Larchmont, N.Y.) 15, 48-55. doi:10.1089/vbz.2014.1621

John, A. (2014). Rodent outbreaks and rice pre-harvest losses in Southeast Asia. Food Security 6, 249-260. doi:10.1007/s12571-014-0338-4

Kosoy, M., Khlyap, L., Cosson, J.-F., and Morand, S. (2015). Aboriginal and invasive rats of genus Rattus as hosts of infectious agents. Vector-Borne and Zoonotic Diseases (Larchmont, N.Y.) 15, 3-12. doi:10.1089/ vbz.2014.1629

Kuo, C.-C., Wang, H.-C., and Huang, C.-L. (2011). The potential effect of exotic Pacific rats Rattus exulans on vectors of scrub typhus. Journal of Applied Ecology 48, 192-198. doi:10.1111/j.1365-2664.2010.01909.x

Lack, J. B., Greene, D. U., Conroy, C. J., Hamilton, M. J., Braun, J. K., Mares, M. A., and Van Den Bussche, R. A. (2012). Invasion facilitates hybridization with introgression in the Rattus rattus species complex. Molecular Ecology 21, 3545-3561. doi:10.1111/j.1365-294X.2012. 05620.x

Lambin, E. F., Tran, A., Vanwambeke, S. O., Linard, C., and Soti, V. (2010). Pathogenic landscapes: interactions between land, people, disease vectors, and their animal hosts. International Journal of Health Geographics 9, 54. doi:10.1186/1476-072X-9-54

Latinne, A., Waengsothorn, S., Rojanadilok, P., Eiamampai, K., Sribuarod, K., and Michaux, J. (2012). Combined mitochondrial and nuclear markers revealed a deep vicariant history for Leopoldamys neilli a cave-dwelling rodent of Thailand. PLOS ONE 7, e47670. doi:10.1371/ journal.pone. 0047670

Latinne, A., Waengsothorn, S., Rojanadilok, P., Eiamampai, K., Sribuarod, K., and Michaux, J. R. (2013a). Diversity and endemism of Murinae rodents in Thai limestone karsts. Systematics and Biodiversity 11, 323-344. doi:10.1080/14772000.2013.818587

Latinne, A., Chaval, Y., Waengsothorn, S., Rojanadilok, P., Eiamampai, K., Sribuarod, K., Herbreteau, V., Morand, S., and Michaux, J. R. (2013b). Is Leopoldamys neilli (Rodentia, Muridae) a synonym of Leopoldamys herberti? A reply to Balakirev et al. (2013). Zootaxa 3731, 589-598. doi:10.11646/zootaxa.3731.4.10

Lecompte, E., Aplin, K., Denys, C., Catzeflis, F., Chades, M., and Chevret, P. (2008). Phylogeny and biogeography of African Murinae based on mitochondrial and nuclear gene sequences with a new tribal classification of the subfamily. BMC Evolutionary Biology 8, 199. doi:10.1186/1471-2148-8-199

Leliaert, F., Verbruggen, H., Vanormelingen, P., Steen, F., Lopez-Bautista, J. M., Zuccarello, G. C., and De Clerck, O. (2014). DNA-based species delimitation in algae. European Journal of Phycology 49, 179-196. doi:10.1080/09670262.2014.904524

Makundi, R., and Massawe, A. (2011). Ecologically based rodent management in Africa: potential and challenges. Wildlife Research 38, 588-595. doi:10.1071/WR10147

McFarlane, R., Sleigh, A., and McMichael, T. (2012). Synanthropy of wild mammals as a determinant of emerging infectious diseases in the Asian-Australasian region. EcoHealth 9, 24-35. doi:10.1007/s10393012-0763-9

Meerburg, B., Singleton, G. R., and Kijlstra, A. (2009). Rodent-borne diseases and their risks for public health. Critical Reviews in Microbiology 35, 221-270. doi:10.1080/10408410902989837

Milocco, C., Kamyingkird, K., Desquesnes, M., Jittapalapong, S., Herbreteau, V., Chaval, Y., Douangboupha, B., and Morand, S. (2013). Molecular demonstration of Trypanosoma evansi and Trypanosoma lewisi DNA in wild rodents from Cambodia, Lao PDR and Thailand. Transboundary and Emerging Diseases 60, 17-26. doi:10.1111/j.1865-1682.2012. 01314.x

Monath, T. P. (1975). Lassa fever: review of epidemiology and epizootiology. Bulletin of the World Health Organization 52, 577-592.

Morand, S., and Clairon, N. (2014). BiodivHealthSEA. Biodiversité et Santé en Asie du Sud-est. Ingénerie des Systèmes d'Information (Networking and Information Systems) 19, 175-179.

Morand, S., Jittapalapong, S., Supputamongkol, Y., Abdullah, M. T., and Huan, T. B. (2014). Infectious diseases and their outbreaks in AsiaPacific: biodiversity and its regulation loss matter. PLOS ONE 9, e90032. doi:10.1371/journal.pone.0090032

Morand, S., Bordes, F., Blasdell, K., Pilosof, S., Cornu, J.-F., Chaisiri, K., Chaval, Y., Cosson, J.-F., Claude, J., Feyfant, T., Herbreteau, V., Dupuy, S., and Tran, A. (2015). Assessing the distribution of disease-bearing rodents in human-modified tropical landscapes. Journal of Applied Ecology. doi:10.1111/1365-2664.12414

Musser, G., and Carleton, M. (2005). Superfamily Muroidea. In: 'Mammal Species of the World: A Taxonomic and Geographic Reference, Volume 2'. 3rd edn. (Eds D. E. Wilson and D. M. Reeder.) pp. 894-1531. (Johns Hopkins University: Baltimore.) 
Myers, N., Mittermeier, R. A., Mittermeier, C. G., da Fonseca, G. A., and Kent, J. (2000). Biodiversity hotspots for conservation priorities. Nature 403, 853-858. doi:10.1038/35002501

Nitatpattana, N., Chauvancy, G., Jumronsawat, K., Poblap, T., Yoksan, S., and Gonzalez, J.-P. (2000). Preliminary study on potential circulation of arenaviruses in the rodent population of Nakhon Pathom Province, Thailand and their medical importance in an evaluating environment. The Southeast Asian Journal of Tropical Medicine and Public Health 31, 62-65.

Ostfeld, R. S. (2009). Biodiversity loss and the rise of zoonotic pathogens. Clinical Microbiology and Infection 15(Suppl. 1), 40-43. doi:10.1111/ j.1469-0691.2008.02691.x

Ostfeld, R. S., Glass, G. E., and Keesing, F. (2005). Spatial epidemiology: an emerging (or re-emerging) discipline. Trends in Ecology \& Evolution 20, 328-336. doi:10.1016/j.tree.2005.03.009

Pagès, M., Chaval, Y., Herbreteau, V., Waengsothorn, S., Cosson, J.-F., Hugot, J.-P., Morand, S., and Michaux, J. (2010). Revisiting the taxonomy of the Rattini tribe: a phylogeny-based delimitation of species boundaries. BMC Evolutionary Biology 10, 184. doi:10.1186/1471-2148-10-184

Pagès, M., Bazin, E., Galan, M., Chaval, Y., Claude, J., Herbreteau, V., Michaux, J., Piry, S., Morand, S., and Cosson, J.-F. (2013). Cytonuclear discordance among Southeast Asian black rats (Rattus rattus complex). Molecular Ecology 22, 1019-1034. doi:10.1111/mec.12149

Palmeirim, M., Bordes, F., Chaisiri, K., Siribat, P., Ribas, A., and Morand, S. (2014). Helminth parasite species richness in rodents from Southeast Asia: role of host species and habitat. Parasitology Research 113, 3713-3726. doi:10.1007/s00436-014-4036-0

Paull, S. H., Song, S., McClure, K. M., Sackett, L. C., Kilpatrick, A. M., and Johnson, P. T. (2012). From superspreaders to disease hotspots: linking transmission across hosts and space. Frontiers in Ecology and the Environment 10, 75-82. doi:10.1890/110111

Pons, J., Barraclough, T. G., Gomez-Zurita, J., Cardoso, A., Duran, D. P., Hazell, S., Kamoun, S., Sumlin, W. D., and Vogler, A. P. (2006). Sequence-based species delimitation for the DNA taxonomy of undescribed insects. Systematic Biology 55, 595-609. doi:10.1080/ 10635150600852011

Pumhom, P., Pognon, D., Yangtara, S., Thaprathorn, N., Milocco, C., Douangboupha, B., Herder, S., Chaval, Y., Morand, S., Jittapalapong, S., and Desquesnes, M. (2014). Molecular prevalence of Trypanosoma spp. in wild rodents of southeast Asia: influence of human settlement habitat. Infection and Epidemiology 142, 1221-1230. doi:10.1017/ S0950268813002161

Pumhom, P., Morand, S., Tran, A., Jittapalapong, S., and Desquesnes, M. (2015). Trypanosoma from rodents as potential source of infection in human-shaped landscapes of South-East Asia. Veterinary Parasitology 208, 174-180. doi:10.1016/j.vetpar.2014.12.027

Püttker, T., Meyer-Lucht, Y., and Sommer, S. (2008). Effects of fragmentation on parasite burden (nematodes) of generalist and specialist small mammal species in secondary forest fragments of the coastal Atlantic Forest, Brazil. Ecological Research 23, 207-215. doi:10.1007/s11284-007-0366-Z

Rickart, E. A., Balete, D. S., Rowe, R. J., and Heaney, L. R. (2011). Mammals of the northern Philippines: tolerance for habitat disturbance and resistance to invasive species in an endemic fauna. Diversity \& Distributions 17, 530-541. doi:10.1111/j.1472-4642.2011.00758.x

Robins, J. H., Hingston, M., Matisoo-Smith, E., and Ross, H. (2007). Identifying Rattus species using mitochondrial DNA. Molecular Ecology Notes 7, 717-729. doi:10.1111/j.1471-8286.2007.01752.x

Robins, J. H., McLenachan, P. A., Phillips, M. J., Craig, L., Ross, H. A., and Matisoo-Smith, E. (2008). Dating of divergences within the Rattus genus phylogeny using whole mitochondrial genomes. Molecular Phylogenetics and Evolution 49, 460-466. doi:10.1016/j.ympev.2008. 08.001

Robins, J. H., McLenachan, P. A., Phillips, M. J., McComish, B. J., MatisooSmith, E., and Ross, H. A. (2010). Evolutionary relationships and divergence times among the native rats of Australia. $B M C$ Evolutionary Biology 10, 375.

Rohland, N., and Hofreiter, M. (2007). Comparison and optimization of ancient DNA extraction. BioTechniques 42, 343-352. doi:10.2144/ 000112383

Saisongkorh, W., Wootta, W., Sawanpanyalert, P., Raoult, D., and Rolain, J. M. (2009). 'Candidatus Bartonella thailandensis': a new genotype of Bartonella identified from rodents. Veterinary Microbiology 139, 197-201. doi:10.1016/j.vetmic.2009.05.011

Singleton, G. R. 2003. 'Impacts of Rodents on Rice Production in Asia.' IRRI Discussion Paper Series No. 43. (International Rice Research Institute: Los Baños, Philippines.)

Singleton, G. R., Hinds, L. A., Krebs, C. J., and Spratt, D. M. 2003. 'Rats, Mice and People: Rodent Biology and Management.' (Australian Centre for International Agricultural Research: Canberra.)

Singleton, G. R., Belmain, S., Brown, P. R., Aplin, K., and Htwe, N. M. (2010). Impacts of rodent outbreaks on food security in Asia. Wildlife Research 37, 355-359. doi:10.1071/WR10084

Sodhi, N. S., Koh, L. P., Brook, B. W., and Ng, P. K. L. (2004). Southeast Asian biodiversity: an impending disaster. Trends in Ecology \& Evolution 19, 654-660. doi:10.1016/j.tree.2004.09.006

Steppan, S., Zawadski, C., and Heaney, L. R. (2003). Molecular phylogeny of the endemic Philippine rodent Apomys (Muridae) and the dynamics of diversification in an oceanic archipelago. Biological Journal of the Linnean Society. Linnean Society of London 80, 699-715. doi:10.1111/ j.1095-8312.2003.00274.x

Telfer, S., Birtles, R., Bennett, M., Lambin, X., Paterson, S., and Begon, M. (2008). Parasite interactions in natural populations: insights from longitudinal data. Parasitology 135, 767-781. doi:10.1017/S0031182 008000395

Thaipadungpanit, J., Wuthiekanun, V., Chierakul, W., Smythe, L. D., Petkanchanapong, W., Limpaiboon, R., Apiwatanaporn, A., Slack, A. T., Suputtamongkol, Y., White, N. J., Feil, E. J., Day, N. P. J., and Peacock, S. J. (2007). A dominant clone of Leptospira interrogans associated with an outbreak of human leptospirosis in Thailand. PLoS Neglected Tropical Diseases 1, e56. doi:10.1371/journal.pntd.0000056

Thomson, V., Aplin, K. P., Cooper, A., Hisheh, S., Suzuki, H., Maryanto, I., Yape, G., and Donnellan, S. C. (2014). Molecular genetic evidence for the place of origin of the Pacific rat, Rattus exulans. PLOS ONE 9, e91356. doi:10.1371/journal.pone.0091356

Wells, K., Pfeiffer, M., Lakim, M. B., and Kalko, E. K. V. (2006). Movement trajectories and habitat partitioning of small mammals in logged and unlogged rain forests on Borneo. Journal of Animal Ecology 75, 1212-1223. doi:10.1111/j.1365-2656.2006.01144.x

Wells, K., Kalko, E. K. V., Lakim, M. B., and Pfeiffer, M. (2007). Effects of rain forest logging on species richness and assemblage composition of small mammals in Southeast Asia. Journal of Biogeography 34, 1087-1099. doi:10.1111/j.1365-2699.2006.01677.x

Wilcove, D. S., Giam, X., Edwards, D. P., Fisher, B., and Koh, L. P. (2013). Navjot's nightmare revisited: logging, agriculture, and biodiversity in Southeast Asia. Trends in Ecology \& Evolution 28, 531-540. doi:10.1016/ j.tree.2013.04.005

Willerslev, E., and Cooper, A. (2005). Ancient DNA. Proceedings of the Royal Society B: Biological Sciences 272, 3-16. doi:10.1098/rspb. 2004.2813

Wyatt, K.B., Campos, P.F., Gilbert, M.T.P., Kolokotronis, S.-O., Hynes, W. H., DeSalle, R., Ball, S.J., Daszak, P., MacPhee, R.D.E., and Greenwood, A. D. (2008). Historical mammal extinction on Christmas Island (Indian Ocean) correlates with introduced infectious disease. PloS ONE 3, e3602. doi:10.1371/journal.pone.0003602

Xiao, X., Boles, S., Frolking, S., Li, C., Babu, J.Y., Salas, W., and Moore, B. (2006). Mapping paddy rice agriculture in south and southeast Asia using multi-temporal MODIS images. Remote Sensing of Environment 100, 95-113. doi:10.1016/j.rse.2005.10.004 